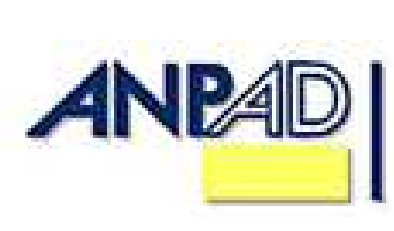

Disponível em

http://www.anpad.org.br/rac

RAC, Rio de Janeiro, v. 16, n. 6, art. 4,

pp. 827-844, Nov./Dez. 2012

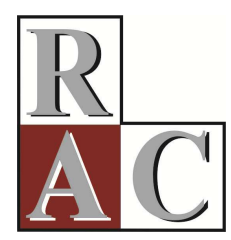

\title{
Racionalidades em Jogo em um Processo de Profissionalização Organizacional
}

\section{Rationalities in a Process of Organizational Professionalization}

Henrique Muzzio *

E-mail: henrique.muzzio@ufpe.br Universidade Federal de Pernambuco - DCA/PROPAD/UFPE

Recife, PE, Brasil.

* Endereço: Henrique Muzzio

Av. dos Funcionários, s/n., Departamento de Ciências Administrativas, Cidade Universitária, Recife/PE, 50740580 . 


\title{
Resumo
}

Este artigo objetiva apresentar as especificidades envolvidas em um processo de profissionalização numa empresa familiar de grande porte. As empresas familiares são objeto de visões opostas sobre a capacidade de gestores familiares possuírem habilidade para gerenciar um negócio de forma competitiva. No processo de profissionalização aqui analisado, uma alternativa aos valores familiares desencadeou avaliações contraditórias entre os investigados. Utilizando o antagonismo entre uma racionalidade instrumental, associada aqui à visão dos novos gestores profissionais, e uma racionalidade substantiva, vinculada à noção dos antigos empregados, esta pesquisa contrapõe os ditos e os não ditos no espaço simbólico organizacional. Com uso de metodologia qualitativa, a partir de uma estratégia de estudo de caso, foram realizadas entrevistas em três unidades empresariais para posterior análise de conteúdo. Os resultados sugerem uma degradação dos ideais do fundador diante do discurso modernizante implantado pelos gestores profissionais. Observa-se uma diluição do seu legado em nome de outros valores, os quais foram associados a uma questão de competitividade e de longevidade organizacional.

Palavras-chave: empresa familiar; racionalidades instrumental e substantiva; profissionalização; mudança organizacional; valores.

\begin{abstract}
This research has the objective of presenting the conditions of a professionalization process in a family business. Family owned companies host opposing interpretations concerning the capacity family managers have to control a competitive business. In this research, an alternative to family values revealed contradictory interpretations between those being investigated. Using the antagonism between instrumental and substantive rationality, we associate the first type of rationality with the perspective of the new professional managers and the second type of rationality to the perspective of the old workers. We use qualitative approach with case studies developed through interviews at three corporate units. The data was analyzed through content analysis. The results show a degradation of the company founder's ideals due to modernization discourse instigated by professional managers. This reduced the founder's legacy and substituted other values associated with competitiveness and long-term viability.
\end{abstract}

Key words: family business; instrumental and substantive rationalities; professionalization; organizational change; values. 


\section{Introdução}

Este artigo objetiva apresentar as especificidades envolvidas em um processo de profissionalização numa empresa familiar de grande porte. Inspirado no debate da racionalidade instrumental versus racionalidade substantiva, é analisado o processo das visões conflitantes entre os gestores profissionais recém-contratados e os funcionários mais alinhados com os valores organizacionais consolidados. A importância desta pesquisa reside em investigar o fenômeno da profissionalização de empresa familiar de grande porte a partir de lentes paradoxais das racionalidades instrumental e substantiva, foco no qual identificamos uma lacuna na área. E mais, diante da característica peculiar dos estudos qualitativos, este trabalho ainda possui seu valor quando contribui com especificidades simbólicas do universo organizacional, que podem ampliar a pluralidade analítica almejada neste campo de estudo.

Conceitualmente, parte-se do pressuposto de que a empresa familiar é uma organização gerida com a intenção de formar e prosseguir a visão dos negócios detidos por uma coalizão dominante, controlada pelos membros de uma ou de poucas famílias, de maneira que seja potencialmente sustentável entre gerações (Chittoor \& Das, 2007; Hall \& Nordqvist, 2008).

Embora este conceito contemple a perpetuação do controle organizacional nas mãos familiares, na literatura (Sindhuja, 2009), observa-se a defesa de que as condições mercadológicas contemporâneas, bem como as pressões institucionais vinculadas à legitimidade, têm levado uma significativa parcela destas empresas, principalmente aquelas de maior porte econômico, a profissionalizar sua gestão. Este fenômeno acaba por proporcionar um rico campo de análise, onde se busca conhecer como estas organizações lidam com este processo tão complexo, que não se resume a uma burocrática transferência de representatividade, ao contrário, diz respeito também a um intricado sistema de substituição de valores e de relações de poder.

O discurso predominante no âmbito empresarial defende que as organizações precisam ser geridas sob uma forte perspectiva de desempenho, em que a performance é normalmente avaliada com o privilégio de aspectos racionais e instrumentais na tomada de decisão (Serva, 1997). No caso das empresas familiares, as forças mercadológicas ajudam a construir um discurso pelo qual tais organizações não alcançam um nível suficiente de eficiência administrativa porque o poder está nas mãos de membros de uma família, o que levaria ao temor de que as decisões fossem potencialmente contaminadas por aspectos emocionais que influenciariam, direta ou indiretamente, nas práticas organizacionais (Miller \& Le Breton-Miller, 2006).

Se por um lado, as organizações necessitam se preocupar com sua perpetuação e alcançar resultados operacionais suficientes para seu desenvolvimento, por outro lado, não é razoável supor que as perspectivas mais subjetivas, tais como o simbolismo, a cultura organizacional ou as relações familiares, possam ser simplesmente esquecidas.

Neste sentido, o objeto de estudo deste trabalho é o processo de profissionalização de uma grande empresa familiar de origem nacional que atua no mercado varejista de alimentos. O objetivo geral é investigar o contraditório defendido por administradores profissionais, com um discurso aqui associado à visão racional instrumental, por meio da defesa da necessidade de transformações das práticas e dos valores organizacionais, e a visão de parte dos antigos funcionários, em que se observa um discurso associado aos valores organizacionais tradicionais, aqui, relacionados à visão racional substantiva.

A defesa destas perspectivas é feita por meio de discursos, um elemento básico de expressão humana que proporciona um sentido social das coisas, dos eventos e das interações sociais. No discurso é que o indivíduo expõe o que lhe faz sentido. Este discurso não é algo isento, ao contrário, está vinculado a uma ideologia que dá senso à vida do indivíduo e à existência das organizações e que normalmente está vinculada a uma condição dominante, daí a necessidade de se ir além do que foi explicitado. Mas se o discurso delimita uma posição ideológica, o silêncio pode também revelar uma 
não neutralidade na medida em que permite o acesso à contradição entre o dito e o não dito. Os anseios não declarados, as manifestações ocultas, ou as negações podem ser estratégicas e elucidar tanto quanto as opiniões ou as afirmações (Fletcher \& Watson, 2007).

Para alcançar o objetivo especificado o estudo possui mais sete partes, além desta introdução. A primeira explora a concepção teórica da racionalidade instrumental e da racionalidade substantiva. A seção que segue analisa a questão teórica da profissionalização em empresas familiares. A seção seguinte focaliza-se na imagem e no legado do fundador nestes tipos de empresas. Em seguida, são detalhados os procedimentos metodológicos da pesquisa de campo. Posteriormente, é apresentada a empresa objeto do estudo. A próxima seção analisa os resultados da pesquisa de campo. Por último, são feitos os comentários, as análises finais e sugestões de novas pesquisas.

\section{Racionalidade Instrumental x Racionalidade Substantiva}

No contexto social moderno, Max Weber ganha proeminência ao apresentar um modelo de estruturação social formal, a burocracia. Segundo Weber (1999), a burocracia é uma forma de poder em razão de que há a possibilidade de imposição da vontade por parte de alguém ou de algum grupo sobre outros. Entre os objetivos da burocracia está a eliminação das disfunções decorrentes da ausência de uma racionalidade objetiva na ação humana. Weber (1999) defende que a racionalidade é aquilo que qualifica o sentido da ação social. Para o autor, a ação social, como qualquer ação, pode ser determinada: (a) de modo racional referente aos fins: por expectativas no tocante ao comportamento de objetos do mundo exterior e de outras pessoas, utilizando essas expectativas como condições ou meios para alcançar fins próprios, ponderados e perseguidos racionalmente, como sucesso; (b) de modo racional referente aos valores: pela crença consciente no valor - ético, estético, religioso ou qualquer que seja sua interpretação - absoluto e inerente a determinado comportamento como tal, independentemente do resultado; (c) de modo afetivo, especialmente emocional: por afetos ou estados emocionais atuais; (d) de modo tradicional: por costume arraigado (Weber, 1999).

Este autor propôs também uma classificação sobre as formas de racionalidade: (a) prática relação entre a visão e o juízo do indivíduo com uma prática assumida; (b) teórica - relação entre conceitos abstratos precisos e ação humana; (c) substantiva - relação entre os padrões da ação humana e seu contexto, sem necessariamente haver um cálculo em relação ao propósito; (d) formal - relação entre ação e resultado consciente de um propósito.

Especificamente sobre a racionalidade instrumental, podemos caracterizá-la pelas seguintes condições: (a) cálculo - as ações humanas são baseadas em projeções utilitárias, (b) maximização dos resultados - predomínio da eficiência e da eficácia em prejuízo da ética no uso dos recursos, (c) fins metas específicas e calculadas para cada ação humana. Quanto à racionalidade substantiva, suas características são: (a) a autorrealização - processo que leva ao alcance do potencial humano, (b) julgamento ético - ações baseadas em juízo de valor (bom, mau, etc.), (c) valores emancipatórios relacionados ao bem-estar social; (d) autonomia - ação e decisão individual realizada em condição de liberdade (Guerreiro Ramos, 1981; Serva, 1997; Weber, 1999).

A racionalidade substantiva seria, então, uma alternativa à perspectiva de ação pretensamente orquestrada entre meios e fins que garantiriam uma plena eficiência dos meios utilizados para conduzir a um fim apoteótico. Nesta concepção, ética, autonomia e autorrealização, por exemplo, seriam também condutores da ação humana para alcançar objetivos sociais ou organizacionais (Guerreiro Ramos, 1981; Serva, 1997).

Os estudos organizacionais retratam, ao longo do tempo, um predomínio de pensamento que acredita na concepção da ação humana como um processo calculado de maximização de recursos. Reed (1998) chama atenção para o fato de que "as organizações modernas anunciavam o triunfo do 
conhecimento racional e da técnica sobre a emoção e o preconceito humano, aparentemente intratáveis" (p. 67).

Esta pretensa superioridade da racionalidade instrumental foi questionada por autores de distintas perspectivas ontológicas e epistemológicas, como a teoria crítica, representada principalmente pelos autores da escola de Frankfurt e suas críticas em relação à desilusão com os resultados humanos vistos na modernidade. Simon (1970) discute os limites da racionalidade absoluta e defende que nossa ação racional é limitada por nossa capacidade em assimilar todas as nuanças envolvidas no processo social, e mais, não seria viável, por dificuldades de recursos, ponderar todas as alternativas que levariam a uma decisão ótima. $\mathrm{O}$ autor fala sobre uma racionalidade limitada que, a despeito de um discurso econômico de maximização dos recursos, não seria plenamente alcançável em virtude dessas limitações.

No contexto do empreendedorismo, além das tradicionais variáveis econômicas para avaliar o desempenho, Groves, Vance e Choi (2011) apresentam evidências empíricas atinentes a alguns fatores influentes nas decisões, como a intuição, o insight, a emoção e a criatividade que complementam os fatores instrumentais tradicionais. Dunham (2010) argumenta que o modelo de ator racional apresenta como características a orientação para o resultado, o autointeresse e o utilitarismo, a orientação por preferências estáveis e bem-requisitadas, a busca da maximização utilitária e a ação com base em uma racionalidade processual. A autora defende que as concepções da racionalidade têm impedido o desenvolvimento de uma compreensão melhor do processo empreendedor, particularmente quanto à inclusão da ética nesta análise. A rejeição da concepção de maximização da utilidade e o reconhecimento de valores plurais presentes nas escolhas, o engajamento em um processo que enfatiza a percepção, a deliberação, a ação experimental e a reflexão, entre outros aspectos, são exemplos de perspectivas defendidas por Dunham (2010), como alternativa à escolha racional.

A longo do tempo, alguns estudos desenvolvidos no Brasil discutiram e/ou buscaram evidências empíricas em relação à contraposição entre as racionalidades instrumental e substantiva. Serva (1997) preocupa-se com a ausência de demonstração prática da razão substantiva nos métodos administrativos, em organizações produtivas. $O$ autor investiga três organizações da cidade de Salvador (BA) e tem como intuito compreender como a razão instrumental e a razão substantiva se concretizam na prática administrativa, tendo identificado o grau de intensidade do uso da racionalidade substantiva nestas organizações. Margoto, Behr e Paula (2010) evidenciam a perspectiva da racionalidade substantiva em indivíduos que se demitiram de suas organizações como uma forma de negação do domínio burocrático, logrando êxito a partir de uma ação emancipatória. Souza e Carrieri (2011) analisam um grupo teatral e discutem o fazer artístico na contemporaneidade. Os autores encontraram evidência da presença tanto da racionalidade instrumental como da substantiva nas ações do grupo, com predomínio desta última. No lado profissional, os artistas preocupam-se com a sobrevivência; enquanto atores de grupo, evidenciam ações de processos criativos com uma liberdade maior e interações pessoais autênticas. Andrade, Tolfo e Dellagnelo (2012) investigam a contraposição entre as racionalidades instrumental e substantiva e fazem uma aproximação entre psicologia e administração. As autoras caracterizam os sentidos do trabalho com base em referências da psicologia e inferem haver sentidos do tipo substantivo e instrumental atribuídos ao trabalho e que estão imbricados entre si no contexto organizacional. Embora com tais estudos, o campo ainda carece de mais investigações com este foco de análise. Um exemplo é a profissionalização de grandes empresas familiares.

\section{Profissionalização na Empresa Familiar}

A pesquisa sobre empresa familiar tem o usual foco em compreender como estas organizações agem estrategicamente para alcançar competitividade. Para Chrisman, Steier e Chua (2008), individuar a natureza da diferença entre firmas familiares e não familiares e como cada uma delas conduz suas 
ações contribui para o desenvolvimento de uma teoria da empresa familiar, principalmente na relação empresa familiar e performance.

Nas organizações familiares, a cultura e todo o seu escopo estão vinculados principalmente à figura de seu fundador. Esta associação é normalmente construída em razão de um histórico marcado por dificuldades iniciais, em que temas como esforço, trabalho árduo, perseverança, heroísmo, etc., servem de justificativa simbólica para a prosperidade organizacional. O fundador é o líder responsável por promover as mudanças organizacionais e por consolidar o desenvolvimento organizacional.

No início, a empresa é uma fiel representação dos desejos do fundador, em que sua visão do mundo e suas limitações servem de parâmetro para moldar a cultura organizacional (Schein, 2004). Em um processo de profissionalização, não é incomum, nesta fase, o choque de valores entre o fundador e os novos dirigentes, com reflexos diretos no delineamento da cultura organizacional, visto que, normalmente, os gestores não familiares possuem valores diferenciados dos membros familiares.

A partir deste momento, o modelo inspirador inicial de comportamento é colocado em paralelo com os valores dos gestores profissionais. Esta condição acaba por criar um cenário potencialmente rico para as análises simbólicas, dada a complexidade em substituir valores culturais normalmente arraigados no imaginário organizacional.

A profissionalização é compreendida, neste artigo, como um processo em que o poder decisório formal é transferido, no todo ou em parte, para executivos não pertencentes à família fundadora, os quais passam a possuir a incumbência de garantir a perpetuação da empresa (Chittoor \& Das, 2007; Hall \& Nordqvist, 2008).

Podemos considerar a profissionalização em empresas familiares como um momento delicado. Uma possível ruptura com os ideais e os valores familiares pode desencadear trajetórias conturbadas, tanto do ponto de vista econômico-financeiro como no aspecto comportamental (Le Breton-Miller, Miller, \& Steier, 2004).

A discussão sobre a profissionalização está ligada à própria natureza da empresa familiar e envolve fatores econômicos (desempenho empresarial) e não econômicos (capital social). Este capital social é algo complexo e tácito, sendo composto por normas, por valores, pela cooperação, pela visão, pela intenção e pela confiança existentes em uma firma familiar (Pearson, Carr, \& Shaw, 2008).

A visão instrumental sobre o processo de profissionalização orienta-se preponderantemente pelo desempenho organizacional. Sindhuja (2009) evidencia a superioridade da gestão profissional na criação de valor para a empresa sobre a gestão familiar. Yildirim-Oktem e Üsdiken (2010), entre outros argumentos, associam a profissionalização de organizações familiares como um meio adequado para enfrentar o crescimento interno e a complexidade externa, bem como facilitar o acesso a recursos críticos. Zhang e Ma (2009) argumentam que o imperativo mercadológico, as forças institucionais e as tradições culturais impelem as empresas familiares à profissionalização. Especificamente, sobre as tradições culturais, os autores exemplificam o caso chinês, em que as relações sociais são estruturadas em círculos concêntricos, com os membros familiares no centro e os demais na periferia. Porém os benefícios com a profissionalização, alcançados por alguns, conduz a uma mudança cultural e institucional em que é revisto este padrão de relação circular.

Vários autores, por sua vez, defendem a superioridade da empresa familiar e sua possibilidade de ser competitiva em virtude de aspectos comportamentais, culturais ou da possibilidade de acesso a recursos em função de suas características peculiares (Habbershon \& Williams, 1999; Hall \& Nordqvist, 2008; Lambrecht, 2005; Miller \& Le Breton-Miller, 2006; Pearson et al., 2008). Estes argumentos são reforçados ainda por evidências empíricas (Allouche, Amann, Jaussaud, \& Kurashina, 2008; Chrisman, Chua, \& Kellermanns, 2009; Salvato \& Melin, 2008).

A defesa tanto da gestão familiar como da gestão profissional exemplifica um processo de mudança e resistência à mudança, um interesse clássico na análise organizacional. Este debate pode ser analisado também pela ótica dos ideais das racionalidades instrumental e substantiva. Os 
defensores da mudança argumentam pela sua necessidade a partir de pressupostos instrumentais de desempenho. Os que resistem à mudança, comumente, são vistos como aqueles que precisam ser superados para o avanço competitivo da organização.

Mas esta concepção possui contestação. Ford, Ford e D'amelio (2008) analisam a resistência à mudança sobre uma ótica alternativa e afirmam que predomina, na literatura, a defesa em favor dos agentes de mudança, e que o opositor à mudança, não é visto como alguém que pode ter coerência estratégica. Todavia, segundo estes autores, ao assumirem que a resistência à mudança é necessariamente má, os agentes da mudança perdem uma oportunidade de ver o lado positivo da resistência, eliminando desnecessariamente elementos contraproducentes presentes neste processo. Esta análise é um exemplo do debate sobre a racionalidade instrumental versus racionalidade substantiva, que também serve de referência para arguir contra e favoravelmente ao processo de profissionalização de empresas familiares. Especificamente, neste caso, o debate também pode subsidiar a discussão entre os novos valores da gestão profissional e os valores vinculados à imagem e ao legado dos fundadores de organizações familiares.

\section{A Imagem e o Legado do Fundador na Empresa Familiar}

O homem é um criador de símbolos, de linguagens, de crenças, de visões, de ideologias, de mitos, etc., o que permite caracterizar a cultura, em geral, e de uma organização em particular, como um fator social, fruto de um compartilhamento entre seus membros, galgado em valores que o grupo interpretou como adequados para subsidiar seu comportamento e que são válidos para aquela realidade espaço-temporal (Martin, 1992; Pettigrew, 1979; Trice \& Beyer, 1984).

Entre os muitos elementos simbólicos, o foco aqui é a imagem e o legado do fundador. $\mathrm{O}$ conceito de legado emerge quando o comportamento de uma pessoa tem implicações para as gerações futuras em uma comunidade ou sociedade. A sua transmissão ocorre por meio de um processo de socialização conduzido entre as gerações (Berger \& Luckmann, 2004). Deixar um legado permite que as pessoas criem algo que irá sobreviver além de si, assim, fornecendo uma forma simbólica de imortalidade (Wade-Benzoni, Sondak, \& Galinsky, 2010).

Segundo Dobel (2005), em um âmbito abstrato, o legado estende-se em diferentes perspectivas, tais como a magnitude da contribuição para ações futuras, a durabilidade do impacto de uma ação, a mutação do significado e das consequências de uma ação ao longo do tempo, ou o legado é relacionado a uma pessoa que recebe créditos pela realização de um resultado. Esta última perspectiva pode ser exemplificada por meio do papel dos líderes ou dos fundadores na condução e na longevidade organizacionais.

Walsh e Glynn (2008) analisam o legado organizacional e comentam sobre a importância dos líderes na criação e perpetuação do mesmo. Estes líderes seriam responsáveis por dar sentido aos eventos do passado e levá-los a construir o futuro. Para estes autores, o legado pode ocorrer na forma tangível, como os artefatos ou as propriedades; e na forma intangível, tais como as tradições, as normas culturais, as crenças ideológicas ou os atributos de identidade.

Quanto à imagem, esta molda a força da identificação dos membros com uma organização e serve como ponto de referência cognitiva que conecta ou desconecta um membro a esta organização (Dutton, Dukerigh, \& Harquail, 1994). A imagem, no sentido metafórico, é compreendida como uma representação mental coletiva que é construída de uma organização (Gioia, Schultz, \& Corley, 2000) ou de alguém. O significado de imagem está relacionado a um contexto histórico, social e cultural específico e se refere a uma projeção que conforma o que um grupo percebe como valores e exigências institucionalizadas (Zilber, 2006).

Simbolicamente, a imagem e o legado dos fundadores normalmente estão associados a valores épicos. A saga da criação empresarial, por exemplo, simboliza um momento de dificuldade que o 
fundador supera de forma heroica. Esta epopeia acaba por servir de referência aos funcionários como um modelo a ser seguido e respeitado, transformando o momento de criação em um evento de forte conteúdo simbólico que se espera ser reforçado ao longo do tempo.

Embora não seja uma exclusividade destas, as organizações familiares constituem um espaço privilegiado para se analisar o simbolismo, pois os laços familiares potencializam o compartilhamento de determinados valores que facilitam a compreensão de certos comportamentos. Um exemplo é a associação entre a família e a empresa, usada como uma estratégia para conseguir uma maior coesão entre seus funcionários, quando um forte discurso associando o corpo funcional a uma grande família fica presente no imaginário coletivo e, muitas vezes, é usado como instrumento de legitimação de ações organizacionais e incentivo ao maior comprometimento funcional. Os críticos desta relação afirmam que tal condição é modelo de uma postura instrumental e interpretam que a intenção desta coesão é muito mais uma busca de produtividade empresarial do que a procura por um bem-estar funcional.

A associação da família com a empresa beneficiaria a formação de uma imagem positiva do fundador, bem como de seu legado que será deixado para as gerações futuras, criando um imaginário que exalta a figura do instituidor e os seus valores, os quais passam a servir como referência para a empresa familiar.

Todavia essas organizações podem ser vistas além de sua conotação simbólica, notadamente no campo mercadológico, onde se induz que elas tenham um comportamento competitivo. Neste sentido, no decurso do tempo, a imagem e o legado do fundador podem significar, para determinados agentes, uma condição não mais suficiente para que a organização cresça e se perpetue. A partir de então, é possível a identificação de ações simbólicas baseadas em discursos bem-distintos. No primeiro, geralmente ancorado na racionalidade instrumental, evidencia-se a necessidade de mudança, de ampliação da produtividade e da competitividade. Por sua vez, discursos de resistência à mudança e de defesa dos ideais do fundador normalmente ecoam com um conteúdo simbólico que pode se refletir nos ideais de uma racionalidade substantiva.

\section{Metodologia}

Esta pesquisa foi realizada em uma grande empresa familiar, nesta pesquisa, denominada como Empresa Alfa, com atuação no segmento de varejo de alimentos. Foram pesquisadas três unidades funcionais, a matriz, situada no Estado do Ceará, e duas filiais, situadas nos estados de São Paulo e Paraná.

O estudo caracteriza-se como analítico descritivo de um contexto específico e utiliza como estratégia de pesquisa o Estudo de Caso, com reconhecida consolidação na pesquisa qualitativa. Este tipo de pesquisa é voltado para investigar complexas conexões entre as práticas em ambientes naturais e algumas abstrações. O nível de análise da pesquisa é o organizacional e a sua unidade são os membros da organização. Os dados foram coletados por meio de acesso a documentos internos (Código de Ética, Prospecto de Emissão de Debêntures, Relatórios para Investidores, Revista Interna), observação simples (realizada nas dependências das três unidades analisadas com acesso autorizado pela empresa para observar as práticas organizacionais e dialogar com funcionários) e, principalmente, a realização de entrevistas semiestruturadas com vinte e duas perguntas abertas.

Gaskell (2002) ressalta a aplicabilidade das entrevistas para mapear e compreender o mundo da vida dos respondentes, constituindo um ponto de entrada para o cientista social introduzir esquemas interpretativos para compreender as opiniões dos atores em termos mais conceituais e abstratos. Este autor vincula seu objetivo à compreensão detalhada das crenças, das atitudes, dos valores e das motivações em relação aos comportamentos das pessoas em determinados contextos sociais. 
Seguindo sugestão de Gibbert e Ruigrok (2010), especificam-se agora as estratégias usadas na condução deste trabalho. A escolha dos participantes ocorreu por meio da técnica bola de neve, em cada unidade funcional. $\mathrm{O}$ acesso aos entrevistados transcorreu sem problemas e nenhum funcionário negou-se a participar do estudo. Vinte e sete entrevistas foram realizadas nas três unidades investigadas ao longo de dois meses.

Vinte e seis entrevistas ocorreram nas respectivas unidades funcionais dos respondentes e uma delas externamente à dependência da empresa por impossibilidade de deslocamento do entrevistado. As entrevistas internas foram realizadas em salas de reuniões e sem a interferência de terceiros. Todas as entrevistas foram gravadas com a autorização dos participantes, que foram informados sobre a natureza do estudo e ainda lhes foi garantida a privacidade individual das respostas. Após a realização das entrevistas, que tiveram duração média de 60 minutos, uma assistente de pesquisa fez as transcrições, que foram revisadas pelo autor deste estudo. Os participantes eram de quatro níveis hierárquicos (Diretoria, Gerência, Supervisão e Coordenação), indicados no decorrer da técnica bola de neve. O total de entrevistas foi delimitado pela saturação de informações.

As entrevistas transcorreram a partir de três eixos temáticos: (a) percepção geral sobre o processo de profissionalização; (b) percepção sobre os valores predominantes antes e após a profissionalização; (c) percepção sobre os influenciadores dos valores antes e depois da profissionalização e as consequências das mudanças ocorridas.

As informações foram tratadas por meio da análise de conteúdo, técnica que encontra larga legitimidade em pesquisas desta natureza. A análise de conteúdo parte do princípio que é possível ao investigador compreender esquemas cognitivos pessoais a partir de um grupo de palavras. Ela fornece uma metodologia replicável de acesso a estruturas individuais ou coletivas profundas, tais como valores, intenções, atitudes e cognições (Duriau, Reger, \& Pfarrer, 2007).

Inicialmente, foi realizada uma análise prévia das transcrições para organização e reconhecimento das narrativas. Em seguida, foi elaborada a análise do material para definição do critério de codificação por frase e para enumeração dos dados, usando como unidade de registro a frequência. Posteriormente, operacionalizou-se a codificação. Foi, então, realizada a interpretação de acordo com os objetivos prévios e as categorias identificadas, a saber: (a) a visão da profissionalização, que analisa as diferenciações de percepção do processo de profissionalização; (b) a velha e a nova Alfa, em que os discursos ficam associados ao simbolismo do novo momento e ao do passado; (c) o legado do fundador e os novos valores, em que se contrapõem os valores que devem nortear a organização, ou aquilo que serviu de modelo no passado ou novos valores associados à profissionalização.

\section{A Empresa Alfa}

Esta pesquisa foi realizada na empresa Alfa (identidade preservada). Estas informações de descrição foram subsidiadas por meio de uma pesquisa documental (Estatuto, Código de ética, Prospecto para investidores financeiros, Revistas internas). A empresa foi criada no estado do Ceará, na década de 1930. Após a experiência em diversos ramos mercadológicos, atualmente, concentra sua atuação em três segmentos econômicos, incluindo o de alimentos, foco desta pesquisa, e que, hoje em dia, é a principal atividade deste grupo empresarial.

$\mathrm{Na}$ época do estudo, a Alfa estava finalizando o processo de profissionalização e, hoje, já se encontra completamente sob a gestão profissional. O processo ocorreu no decurso de cinco anos, com a contratação de diretores e culminou com a efetivação de seu atual presidente, no início de 2011. Era uma empresa familiar de segunda geração. A sua cultura organizacional foi construída e solidificada inicialmente pelo fundador e posteriormente pelos herdeiros. $\mathrm{O}$ fundador já não exerce função 
executiva e um de seus filhos, até então na presidência executiva, passou a comandar o Conselho de Administração, composto exclusivamente por membros da família.

Quanto aos aspectos operacionais e mercadológicos da empresa, atualmente, a Alfa está entre as três maiores empresas brasileiras do setor. Com quase três mil funcionários, suas operações estão presentes em onze estados brasileiros, divididos entre escritórios administrativos, escritórios de vendas, centros de distribuição, unidades fabris e unidades de faturamento que atendem a todas as regiões do país.

O direcionamento estratégico do grupo consiste na transformação da Alfa de uma empresa de commodities em uma empresa com forte atuação e altamente competitiva no segmento de produtos de consumo de alimentos. Segundo sua visão de negócio, a organização busca ser uma empresa de marcas e distribuição com liderança consolidada no mercado de consumo de alimentos, rentabilizando os investimentos existentes e assegurando novos investimentos para o crescimento do negócio com o objetivo de remunerar os acionistas e colaboradores, por meio de uma gestão minuciosamente ajustada, integrada, com atuação em time, de forma complementar e interdependente, de modo que a organização esteja posicionada como uma das empresas mais disputadas para se trabalhar no mercado brasileiro. Esta estratégia é um reflexo da mudança de foco que o grupo desenvolveu para sair do mercado de commodities e focar no mercado de consumo, fato marcante nas práticas e nos valores do grupo nos últimos anos.

A empresa anuncia como seus valores essenciais: (a) ética - estabelecer relações de confiança, agir com senso de justiça e com respeito pelas pessoas e pelo negócio; (b) inovação - perseguir a visão da empresa, com ousadia, atitude empreendedora, senso de urgência e foco em resultados; (c) respeito pelas pessoas - valorizar um ambiente cooperativo, harmônico e saudável entre as pessoas, recompensando desempenhos diferenciados e retendo talentos; (d) compromisso com o negócio compartilhar ideias, defender nossas marcas e buscar a excelência no atendimento aos clientes.

\section{A Profissionalização e o Legado do Fundador na Empresa Alfa}

\section{A visão da profissionalização}

Sob o ponto de vista operacional, o entendimento entre os respondentes é que a profissionalização na Alfa ocorreu de forma bem-sucedida, isto em função de não ter havido conflitos familiares relevantes que prejudicassem o desempenho organizacional nem ter afetado sua trajetória comercial, dado que a empresa continuou a sua expansão com a aquisição de outras concorrentes, bem como consolidou sua posição entre os principais atores nacionais em seu setor de atuação.

Já em âmbito simbólico, esta condição bem-sucedida foi questionada por parte dos respondentes. Expectativas não alcançadas, estresse, insegurança, choques culturais, lutas em função das novas configurações de poder e dúvidas quanto aos valores que serão privilegiados em sua cultura, no futuro, foram exemplos de questões levantadas.

Os objetivos da profissionalização na Alfa não fogem às características encontradas em outros processos semelhantes e do que é ressaltado na literatura referenciada na racionalidade instrumental (Sindhuja, 2009), tais como reduzir a possibilidade de atritos entre os herdeiros e agregados da geração seguinte na condução dos negócios, implantar um gerenciamento com menos influência familiar, garantir a presença de gestores supostamente mais qualificados, etc. Estes objetivos estão baseados na valorização de uma gestão profissionalizada como aquela que é a mais adequada em comparação a uma gestão familiar (Chittoor \& Das, 2007).

Foram observadas opiniões relacionadas a uma perspectiva instrumental da profissionalização, colocando este processo como uma condição ideal que permite à empresa ter mais legitimidade no 
mercado e que a fará capaz de prosseguir competitiva frente aos concorrentes: "É uma empresa sólida ... ela está super profissionalizada nas suas estruturas de diretoria e nas outras gerências" (Coordenadora 02 São Paulo). "A gente tem realmente o nível profissional interno muito grande, você não tem pessoas da família envolvidas na operação, enfim, está chegando aí um time de novos executivos, diretores" (Gerente 02 São Paulo).

"Como é que eu vejo a empresa Alfa, um grupo teoricamente familiar, mas na prática, se profissionalizou muito, hoje em dia temos processos, políticas, os processos não são soltos, eles são bem atrelados, bem amarrados e é uma empresa que eu acho que, para o mercado de Fortaleza e em nível Brasil onde ele atua, ela inspira profissionalismo, seriedade" (Coordenadora 02 Fortaleza).

Estes depoimentos evidenciam uma perspectiva de racionalidade instrumental ao processo de profissionalização ao atrelarem esta condição a uma situação ideal de governança (Yildirim-Oktem \& Üsdiken, 2010; Zhang \& Ma, 2009). O gerente de São Paulo ressalta que não há mais executivos da família na empresa, em uma expressão de positividade por esta ausência. A respondente de Fortaleza afirma que a condição familiar da empresa é apenas teórica, fato passível de contestação, pois a condução das diretrizes estratégicas é dada pelos membros da família fundadora que dominam o seu conselho de administração. $\mathrm{O}$ uso da expressão superprofissionalizada, por parte de uma respondente de São Paulo, também, ajuda a ilustrar, em tese, o simbolismo das boas práticas, do resultado superior, da qualidade dos processos da empresa não familiar, embora esta condição não seja uma sentença de má gestão conforme alguns autores (Allouche et al., 2008; Hall \& Nordqvist, 2008; Lambrecht, 2005).

O processo de profissionalização da empresa Alfa evidenciou a distinção entre a racionalidade instrumental e a substantiva (Serva, 1997), existindo aparentemente uma tentativa de inclusão de novos valores em sua cultura organizacional, desvinculados da questão familiar. Este processo gerou uma reinterpretação da imagem do fundador (Dutton et al., 1994; Zilber, 2006) e os valores a ele associados, bem como arrefece o seu legado (Wade-Benzoni et al., 2010).

\section{A velha e a nova Alfa}

Ao longo do processo de mudança, novos valores são acrescentados e a necessidade de mudança emerge do cotidiano organizacional como algo obrigatório (Ford, Ford, \& D'amelio, 2008). Surge então uma dicotomia carregada de simbolismo entre o futuro e o passado, ou nas palavras de alguns, entre a velha Alfa e a nova Alfa:

\footnotetext{
"Vendo há dois anos e você olhar como está hoje, ela é outra empresa, eu entrei em uma empresa, hoje eu estou numa outra empresa, não é? E que a cada mês o processo de mudança continua ... a cada mês é uma nova Alfa" (Gerente 02 São Paulo).

"Nós temos que mudar também as pessoas, não mudar, trocar de pessoas, mas mudar a mentalidade das pessoas, mudar a cabeça das pessoas, nesse sentido, através de um trabalho realmente de uma mudança cultural, ela não é num estalar de dedos, ela tem que ser paulatina e gradual, ao longo de um tempo, dois meses, três meses, um ano, dois anos, e aí algumas pessoas resistem mais e outras menos, mas foi realmente um trabalho que nós tivemos que fazer" (Gerente 01 Fortaleza).
}

A ruptura com o passado, incluindo os valores familiares e os culturais vinculados ao fundador, é uma estratégia para aqueles que defendem a mudança. Os novos executivos precisam associar suas contratações a um novo tempo que rompe simbolicamente com o passado e pode ser exemplificado quando o respondente que já trabalhava na empresa anteriormente afirma que trabalha "numa outra empresa".

Já a velha Alfa é reproduzida nos discursos dos respondentes pela influência que a presença do fundador acarreta, principalmente na sede da empresa. O Conselho de Administração e os escritórios dos membros da família ficam sediados nas instalações da unidade Fortaleza. Tal proximidade física acaba por influenciar o comportamento de seus funcionários e deixa a questão familiar e os valores a ela vinculados mais vivos na matriz da empresa: "essa unidade, ela recebe praticamente a visita diária do patrono e essas visitas, elas mantêm a chama acesa da cultura da organização" (Coordenador 03 
Fortaleza). "Isso é uma coisa que eu acho ímpar, você vê o proprietário da empresa, chega e fala com você, conversa tudo, não importa qual seja o teu cargo, do mais simples ao mais alto, chega pergunta..." (Gerente 01 Fortaleza).

"O Presidente [do Conselho] está aqui, que é o fundador da empresa, ele se encontra aqui, ele vem todos os dias na empresa, a família e os acionistas se encontram na empresa, apesar de agora a empresa ter um capital aberto, então assim, os acionistas que fazem parte do grupo estão aqui" (Cordenadora 02 Fortaleza).

Por sua vez, nas unidades de São Paulo e de Londrina (Paraná), esta presença já não é marcante e a imagem do fundador e os valores a ela associados (Zilber, 2006) parecem diluir-se com um novo discurso proferido pelos gestores profissionais, como ilustrado pela Coordenadora 03 Londrina, ao comparar a gestão familiar e a profissionalizada no âmbito dos recursos humanos:

"Eu admirava muito, mas eu não vejo hoje assim um destaque. O capital humano era muito valorizado, mas eu não vejo isso hoje, ele está voltando para o passado. Então, também foi um dos motivos que me fez ficar, realmente as pessoas eram valorizadas, mas hoje mudou muita coisa".

Nos discursos, percebe-se o paradoxo entre os valores associados a uma racionalidade instrumental, com a sua defesa de necessidade de mudança em nome de uma gestão mais qualificada e necessária para alcançar resultados competitivos, e os associados a uma racionalidade substantiva, em que o participante vê negados valores que outrora, em sua percepção, eram vistos como adequados. O discurso de mudança e da profissionalização é muito presente (Zhang \& Ma, 2009) e parece buscar sua vinculação à qualidade do novo, enquanto outros buscam, nas condições do passado, algo que ainda permita uma conexão deste indivíduo com a organização (Dutton et al., 1994).

\section{Legado do fundador e os novos valores}

A profissionalização fez emergir com mais força uma distinção entre os valores que importam para a Alfa seguir sua trajetória. Isto está presente nas ideias, nos processos e na tentativa de mudança cultural que se materializam nos discursos dos respondentes.

Valores como rapidez nos resultados, agilidade, senso de urgência, total dedicação, etc., simbolizam os novos valores da profissionalização. Outros valores mais ligados à figura do fundador, como o tempo de serviço dos funcionários na empresa e uma gestão mais humanizada, perdem força no imaginário organizacional.

"A principal mudança da Alfa foi a mudança de atitude, de posturas e de pessoas não é? Então, a gente vem, em cada dia que passa, quebrando paradigmas, a cada dia que passa, a gente vem tentando construir, vamos dizer assim, uma nova cultura, quando falo em nova cultura a gente fala em algo voltado para o business e enxergar o nosso negócio como um negócio diferente do que era no passado, uma empresa de commodities, e hoje o produto é totalmente diferente, eu não vendo nenhum produto, hoje, eu vendo marca, então, isso é uma mudança cultural interna absurda" (Gerente 02 São Paulo).

Um legado do fundador, que surgiu nos depoimentos, refere-se à política da empresa Alfa em ser, segundo alguns respondentes com mais tempo de serviço, uma cumpridora fiel das obrigações tributárias, fato atribuído, por eles, ao fundador, que teria tornado isto um dogma, como visto neste depoimento:

"A empresa se orgulha, desde o nosso fundador, ela se orgulha de ser uma empresa $100 \%$ na legalidade, essa empresa, ela tem um valor ético, moral muito forte, e isso vem desde seu fundador até os filhos que hoje estão pilotando a empresa, nessa organização existe uma ordem, aliás, duas ordens do fundador, uma é não sonegar um centavo e a outra é não atrasar um dia sequer o pagamento de seus funcionários" (Coordenador 01 Fortaleza).

Mas, quando se contrasta estes valores com os discursos, é notado um distanciamento entre eles. Além de dois respondentes, não foi registrado outro depoimento sobre esta condição honesta ou mesmo a exaltação de uma conduta ética. Não parece uma situação razoável que a maioria dos 
respondentes não tenha feito referência a estes valores. Será que este dogma do fundador ainda norteia as práticas operacionais na empresa? Embora não tenha aparecido explicitamente nas respostas dos participantes, o silêncio (Fletcher \& Watson, 2007) da maioria deles dá pistas de que há uma mudança de comportamento em curso, ainda que o não dito, necessariamente, signifique ausência, mas apenas um esquecimento.

Outra questão refere-se ao mito da grande família influenciada pelo fundador. A participação dos funcionários neste contexto, normalmente, está vinculada a uma satisfação em fazer parte de uma organização ou mesmo ter orgulho em ser um de seus membros. Porém o que se vê, entre muitos dos respondentes, são dados que não condizem com esta imagem. Quando indagados sobre as suas percepções a propósito de suas unidades funcionais, poucos fizeram referência à questão do orgulho ou prazer em trabalhar na empresa Alfa. Este não dito pode ser um indicativo de que os funcionários já não percebem a empresa como um símbolo de família, como fora no passado, bem como pode expressar um descontentamento com as mudanças desencadeadas pela nova gestão profissionalizada. Os novos processos, as novas práticas organizacionais e a cultura em transformação parecem descortinar o imaginário dos participantes de que os novos tempos começam a diluir muito os valores consolidados.

Em outro aspecto da pesquisa, foram analisados os fatores que os funcionários atribuíam à trajetória de mais de setenta anos da empresa Alfa e sua posição como um dos principais atores do país em seu setor. Entre as razões apontadas pelos respondentes estão: a qualidade dos produtos comercializados, a postura da empresa perante fornecedores e clientes, bem como as ações empreendedoras do fundador. Contudo esta última razão é citada por não mais do que três entrevistados. Se for levada em consideração a importância normalmente atribuída ao fundador para o sucesso dos negócios em empresas familiares (Hall \& Nordqvist, 2008), esta ausência sugere que o legado do criador (Dobel, 2005; Walsh \& Glynn, 2008) está dissipado entre os funcionários da Alfa. Ainda que exista um respeito pela sua trajetória e postura empreendedora, isto já não mais é tão visto como algo responsável pela posição da empresa atualmente, ou mais, pela sua expectativa de continuidade.

Simbolicamente, para os respondentes, um dos principais motivos para a consideração desta nova Alfa, em que o legado do fundador perde sua força na cultura organizacional, foi a reorientação estratégica de commodities para o mercado de consumo. Com isso, a empresa deixou de atender a clientes do segmento de atacado, com grandes volumes concentrados em poucos clientes cativos, e passou a atender ao mercado varejista, passando a concorrer por um grande número de clientes que compram em pequenas quantidades, o que demandou uma nova postura organizacional. Tal ação foi operacionalizada principalmente pela contratação de funcionários oriundos de uma empresa do mercado de bebidas (aqui, identificada como VBA), conhecida por sua agressividade mercadológica.

Estes novos funcionários trouxeram suas experiências no setor de consumo varejista, junto com os valores da empresa em que trabalhavam anteriormente, e funcionaram como agentes de mudança, introduzindo novas posturas aos empregados da Alfa. Dentro do processo de institucionalização desta nova Alfa, uma das estratégias usadas por estes agentes foi contratar outros funcionários oriundos da VBA, os quais já possuíam um padrão institucional de comportamento considerado legítimo e adequado ao novo momento da empresa analisada:

"Você tem muitas pessoas que entendem e que continuam aí com o processo e tem muitas pessoas que, infelizmente, não é que são ruins ou que são boas, são pessoas que têm outra cultura enraizada e, aí, a gente tem que trocar peças, não é?" (Gerente 02 São Paulo).

"A gente montou uma equipe completamente nova, então eu tenho as pessoas que respondem para mim diretamente, eu tenho sete pessoas hoje direto que ficam comigo e tenho mais toda a estrutura do campo que são os PCPs, da fábrica em geral, que são indiretos. Dos sete que eu tenho direto comigo, só dois são mais antigos, cinco são novos e dos cinco novos quatro são ex VBA.... A gente sabe que quando a gente fala com um cara da ex VBA 'escuta, precisamos ralar, precisamos trabalhar pra cacete!', o cara sabe o que é virar a noite, o cara sabe o que é sair daqui do trabalho meia-noite, trabalhar sábado, domingo, 
feriado sem achar ruim, porque ele vê que isso é necessário para construir mais rápido o resultado consistente" (Gerente 04 São Paulo).

Parece que esta nova maneira de agir de alguns acabou chocando-se com os valores enraizados na Alfa e que sofriam influência do fundador. Entre aqueles que não foram demitidos, os ressentimentos estão vivos na memória, e os episódios ainda não estão completamente superados, como ilustra o depoimento a seguir: "a busca por resultado, muitas vezes, atropela o humano, há um desgaste muito grande, aquelas pessoas que não suportam essa velocidade acabam saindo" (Coordenadora 03 de Londrina). Esta substituição de funcionários que não absorvem esta nova ordem é evidenciada pelo depoimento do gerente de São Paulo quando este refere: "são pessoas que têm outra cultura enraizada e aí a gente tem que trocar peças, não é?’.

Estes dados evidenciam a força dos gestores profissionalizados na condução da Alfa. Ancorado em um discurso de mudar ou morrer, viu-se uma tentativa de impor uma nova cultura organizacional que seria responsável pelo sucesso e alcance de metas racionais (instrumentais). Ainda assim, é reconhecido que uma mudança cultural não ocorre com a celeridade que, talvez, estes gestores desejem (Martin, 1992). É razoável supor que muito da velha Alfa ainda irá persistir no imaginário dos antigos funcionários, bem como os valores associados ao fundador, ainda que seu legado esteja em processo de dissipação.

\section{Considerações Finais}

Prevalece, na indústria do management, um discurso instrumental que exalta a necessidade de mudanças nas organizações para que estas possam garantir a competitividade e o alcance de objetivos crescentes de desempenho. Neste contexto, há uma supervalorização da celeridade, da flexibilidade, do novo, etc., valores que crescem em importância em razão da força que a racionalidade instrumental exerce no mundo empresarial (Reed, 1998).

Em paralelo a esta racionalidade, as organizações são detentoras, em maior ou menor grau, de uma racionalidade substantiva (Guerreiro Ramos, 1981) que lhes faz contraponto. É o caso ilustrado, nesta pesquisa, entre a imagem e o legado do fundador de uma empresa familiar e os novos valores que emergem do processo de profissionalização.

Na empresa investigada, a despeito de uma imagem positiva do fundador e do reconhecimento da grandeza de sua trajetória, os valores a ele associados, em geral, não são mais vistos pelos funcionários como algo tão presente nos ideais e nas práticas empresariais. Isso ocorre quando os gestores profissionais buscam demonstrar que os valores associados a uma gestão familiar precisam ser substituídos por lógicas instrumentais que são vendidas como possuidoras de motivos nobres, tais como ganhar maior legitimidade do mercado ou garantir o patrimônio da família como acionista. Com isso, o próprio simbolismo é usado como meio para diluir o conteúdo simbólico que cerca a imagem do fundador. Não para depreciar ou reduzir a importância de seu feito histórico neste caso, mas, sim, para legitimar que a mudança é algo imprescindível à sobrevivência da empresa a longo prazo.

O processo de profissionalização em empresas familiares, como a maioria das mudanças, não é um processo simples (Le Breton-Miller et al., 2004), assim, a existência do contraditório pode ser considerada natural. Na empresa Alfa, o discurso da profissionalização proferido por alguns busca legitimar uma necessária condição de mudança defendida pelos gestores recém-contratados, que passa por uma redução dos ideais de seu fundador e da valorização das novas ideias defendidas por estes executivos.

Observa-se um processo de diluição deste legado em nome de outros valores que foram associados a uma questão de competitividade e longevidade. Conquanto os gestores profissionais busquem implantar um discurso associado à racionalidade instrumental, esta visão não é suficiente para contemplar a totalidade da empresa investigada, principalmente no seu contexto simbólico, o que 
propicia as contradições entre os respondentes. As resistências à mudança podem significar que a mudança em si não é necessariamente melhor para a organização, talvez, este contraditório seja até benéfico para a mesma (Ford et al., 2008). As visões antagônicas podem garantir a existência de um debate que permita oferecer alternativas de ação, evitando, dessa maneira, uma condição nem sempre adequada para a gestão organizacional: aquela em que não há outra alternativa a seguir!

$\mathrm{O}$ embate entre a racionalidade instrumental e a racionalidade substantiva ficou evidenciado neste estudo. As suas especificidades e dimensões, aqui, ressaltadas, bem como a exploração da natureza simbólica desta análise para o campo dos estudos organizacionais, levam ao alcance do objetivo inicialmente proposto.

A partir da lacuna no campo, como especificada na introdução deste trabalho, os resultados desta pesquisa contribuem para o avanço do conhecimento na medida em que oferecem novos subsídios para que pesquisadores e gestores organizacionais melhor compreendam o processo de profissionalização de empresas familiares de grande porte.

Uma observação inicial é que, em organizações de maior porte econômico e com atuação em diferentes unidades empresariais, as práticas de racionalidade substantivas podem estar mais arraigadas e com mais capilaridade em virtude desta condição de grandeza, neste sentido, esforços adicionais são requeridos aos gestores destas organizações para equalizar as ações estratégicas, como a profissionalização, a este fenômeno.

Ainda, do ponto de vista gerencial, seria razoável reconhecermos que os processos de profissionalização desta natureza envolvem questões mais amplas do que vemos comumente nas orientações gerenciais instrumentais. Os aspectos substantivos, simbólicos, familiares, etc., não são eliminados sumariamente por meio de ações racionais instrumentais e, por conseguinte, não é um processo limitado à substituição de valores definidores das estratégias e das práticas organizacionais. Mesmo atos institucionalizados e dotados de poder hierárquico podem não ser suficientes para consolidar no imaginário dos colaboradores, possíveis virtudes administrativas de uma mudança organizacional.

Outra indicação, a partir dos resultados alcançados, é que, em processos de profissionalização de empresas familiares, os novos dirigentes devem desenvolver competência relacional que torne possível a convivência com pessoas e atitudes dissidentes de uma visão oficial, pois, às vezes, táticas mais radicais de enfrentamento em relação à resistência a mudanças, como as demissões, podem não ser suficientes para eliminar uma cultura ou práticas incrustradas no imaginário dos funcionários, anteriormente declaradas como adequadas pelos próprios dirigentes familiares ao longo do tempo.

Quanto às limitações da pesquisa, como defendido por Mattos (2011), em relação a pesquisas qualitativas, estas não podem ser anunciadas comparativamente a pesquisas quantitativas e, neste sentido, afirmar que a impossibilidade de generalização seria uma limitação, pois isto não é seu intuito. As pesquisas qualitativas podem buscar generalizações analíticas, e não estatísticas (Yin, 2003). Assim, pesquisas empíricas adicionais ainda devem ser realizadas para que possamos contribuir com a generalização analítica desta temática. Outro ponto de limitação decorre da ausência de outras técnicas qualitativas que poderiam aprofundar o estudo, como, por exemplo, o uso da etnografia, que poderiam trazer outros resultados aqui não alcançados com a técnica utilizada.

Por fim, como sugestão para robustecer o campo, as futuras investigações podem estender esta pesquisa para diferentes segmentos econômicos ou mesmo explorar outros elementos simbólicos que possam ocorrer em processos de profissionalização de empresas familiares. Pesquisas longitudinais podem ainda analisar os impactos a longo prazo da profissionalização, em que ocorreram processos semelhantes de redução do legado do fundador. Assim como a exploração entre o paradoxo da racionalidade instrumental e da racionalidade substantiva pode ser estendida a outras realidades empíricas.

Artigo recebido em 18.06.2012. Aprovado em 10.09.2012. 


\section{Referências}

Allouche, J., Amann, B., Jaussaud, J., \& Kurashina, T. (2008). The impact of family control on the performance and financial characteristics of family versus nonfamily businesses in Japan: a matched-pair investigation. Family Business Review, 21(4), 315-329. doi: 10.1111/j.17416248.2008.00132.x

Andrade, S. P. C. de, Tolfo, S. R. da, \& Dellagnelo, E. H. L. (2012). Sentidos do trabalho e racionalidades instrumental e substantiva: interfaces entre a administração e a psicologia. Revista de Administração Contemporânea, 16(2), 200-216. Recuperado de http://www.scielo.br/pdf/rac/v16n2/v16n2a03.pdf. doi: 10.1590/S1415-65552012000200003

Berger, P., \& Luckmann, T. (2004). A construção social da realidade (24a ed.). Petrópolis: Ed. Vozes.

Chittoor, R., \& Das, R. (2007). Professionalization of management and succession performance - a vital linkage. Family Business Review, 20(1), 65-79. doi: 10.1111/j.1741-6248.2007.00084.x

Chrisman, J. J., Chua, J. H., \& Kellermanns, F. (2009). Priorities, resource stocks, and performance in family and nonfamily firms. Entrepreneurship Theory \& Practice, 33(3), 739-760. doi: 10.1111/j.1540-6520.2009.00324.x

Chrisman, J. J., Steier, L. P., \& Chua, J. H. (2008). Toward a theoretical basis for understanding the dynamics of strategic performance in family firms. Entrepreneurship Theory \& Practice, 32(6), 935-947. doi: 10.1111/j.1540-6520.2008.00264.x.

Dobel, J. P. (2005). Managerial leadership and the ethical importance of legacy. International Public Management Journal, 8(2), 225-246.

Dunham, L. C. (2010). From rational to wise action: recasting our theories of entrepreneurship. Journal of Business Ethics, 92(4), 513-530. doi: 10.1007/s10551-009-0170-5

Duriau, V. J., Reger, R. K., \& Pfarrer, M. D. (2007). A content analysis of the content analysis literature in organization studies: research themes, data sources and methodological refinements. Organizational Research Methods, 10(1), 5-34. doi: 10.1177/1094428106289252

Dutton, J. E., Dukerigh, J. M., \& Harquail, C. V. (1994). Organizational images and member identification. Administrative Science Quarterly, 39(2), 239-263. doi: 10.2307/2393235

Fletcher, D., \& Watson, T. (2007). Voice, silence and the business of construction: loud and quiet voices in the construction of personal, organizational and social realities. Organization, 14(2), 155-174. doi: 10.1177/1350508407074221

Ford, J. D., Ford, L. W., \& D'amelio, A. (2008). Resistance to change: the rest of the story. Academy of Management Review, 33(2), 362-377. doi: 10.5465/AMR.2008.31193235

Gaskell, G. (2002). Entrevistas individuais e grupais. In M. W. Bauer \& G. Gaskell (Orgs.), Pesquisa qualitativa com texto, imagem e som: um manual prático (pp. 64-89). Petrópolis: Vozes.

Gibbert, M., \& Ruigrok, W. (2010). The "what" and "how" of case study rigor: three strategies based on published work. Organizational Research Methods, 13(4), 710-737. doi: $10.1177 / 1094428109351319$

Gioia, D. A., Schultz, M., \& Corley, K. G. (2000). Organizational identity, image, and adaptive instability. Academy of Management Review, 25(1), 63-81. doi: 10.5465/AMR.2000.2791603 
Groves, K., Vance, C., \& Choi, D. (2011). Examining entrepreneurial cognition: an occupational analysis of balanced linear and nonlinear thinking and entrepreneurship success. Journal of Small Business Management, 49(3), 438-466. doi: 10.1111/j.1540-627X.2011.00329.x

Guerreiro Ramos, A. (1981). A nova ciência das organizações: uma reconceituação da riqueza das nações. Rio de Janeiro: FGV.

Habbershon, T. G., \& Williams, M. L. (1999). A resource-based framework for assessing the strategic advantages of family firms. Family Business Review, 12(1), 1-26. doi: 10.1111/j.17416248.1999.00001.x

Hall, A., \& Nordqvist, M. (2008). Professional management in family businesses: toward an extended understanding. Family Business Review, 21(1), 51-68. doi: 10.1111/j.1741-6248.2007.00109.x

Lambrecht, J. (2005). Multigenerational transition in family businesses: a new explanatory model. Family Business Review, 18(4), 267-282. doi: 10.1111/j.1741-6248.2005.00048.x

Le Breton-Miller, I., Miller, D., \& Steier, L. P. (2004). Towards an integrative model of effective FOB succession. Entrepreneurship Theory \& Practice, 28(4), 305-328. doi: 10.1111/j.15406520.2004.00047.x

Margoto, J. B., Behr, R. R., \& Paula, A. P. P. de (2010). Eu me demito! Evidências da racionalidade substantiva nas decisões de desligamento em organizações. Organização \& Sociedade, 17(52), $115-135$.

Martin, J. (1992). Culture in organizations: three perspectives. New York: Oxford University Press.

Mattos, P. L. C. L. de (2011). "Os resultados desta pesquisa (qualitativa) não podem ser generalizados": pondo os pingos nos is de tal ressalva [Edição Especial]. Cadernos Ebape, 9, 450-468. doi: 10.1590/S1679-39512011000600002

Miller, D., \& Le Breton-Miller, I. (2006). Family governance and firm performance: agency, stewardship, and capabilities. Family Business Review, 19(1), 73-87. doi: 10.1111/j.17416248.2006.00063.x

Pearson, A. W., Carr, J. C., \& Shaw, J. C. (2008). Toward a theory of familiness: a social capital perspective. Entrepreneurship Theory \& Practice, 32(6), 949-969. doi: 10.1111/j.15406520.2008.00265.x

Pettigrew, A. M. (1979). On studying organizational cultures. Administrative Science Quarterly, 24(4), $570-581$.

Reed, M. (1998). Teorização organizacional: um campo historicamente contestado. In S. Clegg, C. Hardy, \& W. Nord (Orgs.), Handbook de estudos organizacionais v. 1: modelos de análise e novas questões em estudos organizacionais (pp. 61-98). São Paulo: Atlas.

Salvato, C., \& Melin, L. (2008). Creating value across generations in family-controlled businesses: the role of family social capital. Family Business Review, 21(3), 259-276. doi: 10.1111/j.17416248.2008.00127.x

Schein, E. H. (2004). Organizational culture and leadership (3rd ed.). San Francisco: Jossey-Bass.

Serva, M. (1997). A racionalidade substantiva demonstrada na prática administrativa. Revista de Administração de Empresas, 37(2), 18-30. doi: 10.1590/S0034-75901997000200003

Simon, H. A. (1970). Comportamento administrativo. Rio de Janeiro: Fundação Getulio Vargas. 
Sindhuja, P. N. (2009). Performance and value creation: family managed business versus non-family managed business. IUP Journal of Business Strategy, 6(3-4), 66-80.

Souza, M. M. P. de, \& Carrieri, A. P. de (2011). Racionalidades no fazer artístico: estudando a perspectiva de um grupo de teatro. Revista de Administração de Empresas, 51(4), 382-395. doi: 10.1590/S0034-75902011000400001

Trice, H. M., \& Beyer, J. M. (1984). Studying organizational cultures through rites and ceremonials. Academy of Management Review, 9(4), 653-669. doi: 10.5465/AMR.1984.4277391

Wade-Benzoni, K. A., Sondak, H., \& Galinsky, A. D. (2010). Leaving a legacy: intergenerational allocations of benefits and burdens. Business Ethics Quarterly, 20(1), 7-34.

Walsh, I. J., \& Glynn, M. A. (2008). The way were: legacy organizational identity and the role of leadership. Corporate Reputation Review, 11(3), 262-276. doi: 10.1057/crr.2008.20

Weber, M. (1999). Economia e sociedade: fundamentos da sociologia compreensiva (Vol. 1). São Paulo: Editora UnB, Imprensa Oficial do Estado de São Paulo.

Yildirim-Oktem, O., \& Üsdiken, B. (2010). Contingencies versus external pressure: professionalization in boards of firms affiliated to family business groups in late-industrializing countries. British Journal of Management, 21(1), 115-130. doi: 10.1111/j.14678551.2009.00663.x

Yin, R. K. (2003). Case study research: design and methods (3rd ed.). California: Sage.

Zhang, J., \& Ma, H. (2009). Adoption of professional management in Chinese family business: a multilevel analysis of impetuses and impediments. Asia Pacific Journal Management, 26(1), 119-139. doi: 10.1007/s10490-008-9099-y

Zilber, T. B. (2006). The work of the symbolic in institutional processes: translations of rational myths in Israeli high tech. Academy of Management Journal, 49(2), 281-303. doi: 10.5465/AMJ.2006.20786073 